\title{
INTRODUCCIÓN. JUAN EDUARDO ZÚÑIGA, NARRADOR REBELDE
}

INTRODUCTION. JUAN EDUARDO ZÚÑIGA, THE REBELLIOUS NARRATOR

LUIS Beltrán Almería

Universidad de Zaragoza

Ibeltran@unizar.es

ÁNGELES ENCINAR

Saint Louis University, Madrid Campus

angeles.encinar@slu.edu

Con poco más de ciento un años nos abandonó Juan Eduardo Zúñiga. En 2019 celebramos su centenario y su extraordinario legado artístico, con este monográfico de Pasavento continuamos el homenaje. Desde niño sintió atracción por las lenguas, al descubrir, en un libro de su padre, una lámina sobre los colosos de Memnón y la leyenda de que hablaban en un idioma desconocido. Esta afición no hizo más que crecer con los años hasta convertirse en un gran especialista en lenguas eslavas. Se interesó primero por la literatura rusa, después por la rumana y la búlgara, y años más tarde por la portuguesa. Tradujo al poeta y pensador Antero de Quental por lo que obtuvo, en 1987, el Premio Nacional de Traducción. La literatura ha sido su principal dedicación: la redacción de su obra, ediciones y prólogos a las de autores admirados -Larra, Chéjov, Yávorov, Pautovski, Turguéniev-, artículos y reseñas. Hablar de la literatura como vida define al hombre y al escritor.

Zúñiga es conocido, sobre todo, por su narrativa breve. "Escribo cuentos porque, en principio, es la medida de mi respiración" (2003: 40), afirmaba en una entrevista con Manuel Longares. Sin embargo, sus dos primeros libros fueron novelas: Inútiles totales de 1951 y El coral y las aguas de 1962, recuperadas por Cátedra (2019). Con la última obtuvo el premio de novela breve de la revista Acento Cultural en 1959. Cuando se publicó en Seix Barral, fue ignorada por la crítica, por colegas y amigos. Esta reacción solo se explica por la obsesión con el realismo social de sus coetáneos. La amistad entre ellos no suponía una afinidad literaria. El coral y las aguas iba "contra corriente". Su realismo metafórico y su lenguaje simbólico resultaban difícil de entender y la localización en la Grecia clásica reforzaba la sensación de extrañamiento. 
En aquellos años de incomprensión, el autor se refugió en otra de sus pasiones: la literatura rusa. Los imposibles afectos de Iván Turguéniev (1977) y El anillo de Pushkin (1983) son dos libros de ensayos sobre escritores predilectos. Temas y motivos de sus obras los recrea con su particular mirada. La frase popular rusa, "El alma ajena es un bosque sombrío", considerada por Zúñiga lema de Turguéniev, planea asimismo en la escritura del madrileño.

Juan Eduardo Zúñiga es maestro del cuento, su magisterio es indiscutible. Así se reconoció al aparecer Largo noviembre de Madrid en 1980. A este se sumó La tierra será un paraíso (1989) y Capital de la gloria (2003), que se reunieron en 2011 con el título La trilogía de la Guerra Civil. "Estos relatos, afirmaba el autor en la presentación (2-XII-2011), presentan una evidente unidad y casi podría aventurar que forman una larga crónica de los tres años que duró la historia dolorosa del cerco de Madrid". El conjunto forma el ciclo de la destrucción de la tierra natal. Con ellos se le conoce en su faceta de escritor de la guerra, vista desde el bando de los perdedores. Sobresale la ceremonia de la destrucción, pero se aprecia también la dimensión regeneradora.

"Una ciudad es, por excelencia, nutritiva sustancia literaria" (2010: 24), admitía Zúñiga. Madrid lo sigue siendo para él en Flores de plomo, ciclo de cuentos en torno a Larra, a quien considera una figura "paradigmática por la modernidad de su pensamiento y su audacia crítica" (2003: 40). Se identifica con él por su visión de la realidad española. Hay en Flores de plomo un aspecto auto-reflexivo y un trasfondo de anhelo de salvación frente al mundo contemporáneo.

La obra de Zúñiga ha sido innovadora, lo ratifica Misterios de las noches y los días. El conjunto de cuarenta relatos muy breves se sumerge en el género fantástico. Lo real se trasgrede por la presencia de lo ilógico, mágico o insólito y se muestra un mundo turbador e inextricable para reflexionar sobre la realidad y la condición humana. Destacan el estilo poético y la complicidad buscada en el lector para desvelar mensajes secretos. En el año 2010 se publicó Brillan monedas oxidadas, una colección de cuentos que realza las características narrativas del autor: el tratamiento de escenarios, la construcción de atmósferas, el dominio de los espacios, la conformación de personajes y la sugerencia.

Por último, Fábulas irónicas, de 2018, representa un esfuerzo de casi medio siglo de escritura. En todas las ficciones se impone una indagación estética en la historia desde una dimensión grotesca que combina la tiranía y la rebeldía, la crueldad y la risa. Recuerdos de vida (2019) reúne fragmentos de memorias con la intensidad y la emoción características de toda su prosa.

Este monográfico recoge ocho ensayos, seis de investigadores (Ana L. Baquero Escudero, Israel Prados, Anthony Pasero-O'Malley, Elena Vega-Sampayo, Raquel de la Varga Llamazares y los dos coordinadores del dossier) y dos de escritores (Danilo Manera, autor y traductor de Zúñiga al italiano, y el narrador Pablo Andrés Escapa, Premio de la Crítica de Castilla y León 2020).

Ana Luisa Baquero Escudero enfoca en su ensayo la primera novela corta de Zúñiga, Inútiles totales, desde una doble perspectiva: la elección genérica y su consideración de germen de toda su poética. Establece que la novela corta ofrece al escritor la posibilidad de ahondar en la trama y de un mayor desarrollo 
de los personajes que en los cuentos. De hecho, Baquero Escudero subraya que esta obra ilustra las existencias de unas marcas características del género (Garrido, Leibowitz). Por otro lado, resalta la presencia del motivo de los dos amigos enamorados de la misma mujer, perteneciente a la tradición literaria, aunque su fuente más próxima sea la literatura de Turguénev en el caso de Zúñiga, motivo que se subsume bajo el tema indicado en el propio título, el hombre inútil.

Israel Prados, autor de la edición crítica de la trilogía de la Guerra Civil, propone una investigación a propósito del espacio literario, el Madrid real y simbólico de Juan Eduardo Zúñiga. Para Prados la ciudad de Madrid (tanto su riqueza referencial como la emblemática) es protagonista de la trilogía de la Guerra no solo desde un punto de vista temático, sino también simbólico, estructural, crítico y genérico. Partiendo del estudio del tiempo en el espacio, Prados defiende la ordenación de la trilogía en sentido espacial -es decir, en el orden cronológico de publicación y no en el orden cronológico histórico en el que ha aparecido la edición más reciente, la de Galaxia Gutenberg-.

El concepto de "Urbicide", acuñado por Martin Coward en 2009 para referirse a la noción de la destrucción total de la ciudad como lugar compuesto por múltiples vivencias singulares y personales, le sirve a Anthony Pasero-O'Malley para una nueva aproximación a los cuentos "Noviembre, la madre, 1936" y "Nubes de polvo y humo", del volumen Largo noviembre de Madrid. Mediante los protagonistas de ambos relatos se incide en temas centrales de toda la colección. Asimismo, el pensamiento de Michel de Certeau con relación a los espacios ("there is no place that is not haunted by many different spirits hidden") y la idea de "hantologie", de Jacques Derrida, permiten a Pasero reconocer en los lugares de estos cuentos una atmósfera fantasmal y así dotar de forma y dimensión a los respectivos espacios a través de los recuerdos.

Elena Vega-Sampayo y José Dávila-Montes recurren al análisis crítico de la cuentística de Zúñiga a partir de varios estratos correspondientes a lo escópico. Se centran en los relatos de Largo noviembre de Madrid para exponer una semántica de la mirada/visión. El resultado viene a concluir que la técnica cuentístico-fotográfica de Zúñiga no se limita a dejar a la vista del lector una foto fija, sino que le obliga a mirar fugazmente por el objetivo de una "cámara" que no es la del narrador. Por el contrario, es la de sus personajes: estos prestan la mirada al lector, y el narrador se diluye como gestor de la transacción.

Luis Beltrán Almería y Ángeles Encinar abordan una de las obras menos estudiadas de Zúñiga, Misterios de las noches y los días. La estética del hermetismo grotesco domina estos misterios en sus dos direcciones: la romántica y la realista, en su doble dimensión, fantástica y satírica. El presente análisis enfoca estas ficciones bajo este prisma y se detiene en la evolución de algunos cuentos sobresalientes. En estas fabulas la unilateralidad del hermetismo pre-moderno se transforma en un pensamiento y una estética que permite una pluralidad de puntos de vista.

Raquel de la Varga Llamazares realiza un estudio comparativo de la obra de Juan Eduardo Zúñiga y de Antonio Pereira, escritores pertenecientes a la Generación del Medio Siglo, por fecha de nacimiento, pero juzgados de extempo- 
ráneos por su alejamiento de las premisas del realismo social de su tiempo; en el caso del primero, se debió a su afección al simbolismo, en el del segundo, por su humanismo y el denostado marbete de autor costumbrista adjudicado. Temas sobresalientes en algunos volúmenes -El ingeniero Balboa y otras historias civiles y La trilogía de la Guerra Civil-, la utilización del género de "ciclos de cuentos", con la posibilidad de realizar una profunda lectura identitaria de algunas colecciones, y, por otro lado, la importancia de los espacios narrativos, son puntales de esta comparación.

En el apartado, "Miradas de autor", Pablo Andrés Escapa, desde una lectura minuciosa y emotiva, subraya su experiencia al conocer la obra de Zúñiga en el año 2003, el mismo de la publicación de su primer libro de cuentos. Considera al autor un maestro fidedigno y subraya su oficio de fabulador bajo el que subsiste un compromiso moral que dota de sentido a toda su escritura. El párrafo inicial del primer cuento de Largo noviembre de Madrid le produjo una conmoción inolvidable. También reconoce en todos los escritores, principiantes y experimentados, una herencia literaria. En Zúñiga, palpita "el latido" de los autores rusos tan queridos por él. El arte narrativo del madrileño convierte a sus libros en un "heraldo de rebeldía y de esperanza", a su juicio.

Danilo Manera, que además de escritor y profesor es traductor del español y del búlgaro al italiano, se fija precisamente en el ciclo eslavo de la obra de Zúñiga. Este ciclo expresa el ensimismamiento del autor, que escapa a un lejano mundo libre, fascinante y distinto de la realidad de la España franquista. Ese ciclo está formado por trabajos como la introducción a los cuentos completos de Antón Chéjov (1962), las traducciones de Vazov, Yóvkov, Yávorov y Paustovskiï, el estudio bio-literario Los imposibles afectos de Iván Turguéniev (1977) que luego se revisará en Las inciertas pasiones de Iván Turguéniev (1996), y los hitos más importantes del "ciclo eslavo": El anillo de Pushkin. Lectura romántica de escritores y paisajes rusos (1983).

Juan Eduardo Zúñiga es un escritor fundamental en la literatura española de los siglos xx y xxı. Desde el inicio de su obra, optó por un simbolismo a la vez realista y mágico para renovar el lenguaje de la novela y el cuento para dar voz a la rebeldía. Ética y calidad literaria han ido siempre de la mano en su producción.

\section{OBRAS CITADAS}

Longares, Manuel (2003): "Una charla con Juan Eduardo Zúñiga", Quimera, n. 227, pp. $36-40$

Zúñiga, Juan Eduardo (2010): Desde los bosques nevados. Barcelona: Galaxia Gutenberg / Círculo de Lectores. 